INTERVENTIONAL CARDIOLOGY AND SURGERY

\title{
Is routine stenting for acute myocardial infarction superior to balloon angioplasty? A randomised comparison in a large cohort of unselected patients
}

\author{
H Suryapranata, G De Luca, A W J van 't Hof, J P Ottervanger, J C A Hoorntje, J-H E Dambrink, \\ A T M Gosselink, F Zijlstra, M-J de Boer
}

Heart 2005;91:641-645. doi: 10.1136/hrt.2004.056705

\begin{abstract}
See end of article for authors' affiliations

Correspondence to: Dr Harry Suryapranata, ISALA Klinieken, Hospital De Weezenlanden, Department of Cardiology, Groot Wezenland 20, 8011 JW Zwolle, Netherlands; h.suryapranata@ diagram-zwolle.nl
\end{abstract}

Accepted 24 January 2005

\begin{abstract}
Objective: To evaluate the impact of routine stenting, compared with balloon angioplasty, in unselected patients presenting with ST segment elevation myocardial infarction (STEMI).

Design: Randomised trial.

Setting: Tertiary referral centre.

Participants: All patients presenting with STEMI randomly assigned to stenting or balloon angioplasty. No exclusion criteria were applied.

Main outcome measure: The primary end point was combined death or reinfarction at one year's follow up.

Results: 1683 consecutive patients with STEMI were randomly assigned before angiography to stenting ( $n=849$ ) or balloon angioplasty $(n=834)$. A total of 785 patients $(92.5 \%)$ in the stent group and 763 patients $(91.5 \%)$ in the balloon group actually underwent primary angioplasty. The groups were comparable in terms of postprocedural TIMI (thrombolysis in myocardial infarction) flow, myocardial blush grade, and distal embolisation. No difference was observed in clinical outcome at both intention to treat (14\% v 12.5\%, not significant) and actual treatment analyses $(12.4 \%$ v $11.3 \%$, not significant).

Conclusions: Compared with balloon angioplasty, routine stenting does not seem to reduce death and reinfarction in a large cohort of unselected patients with STEMI.
\end{abstract}

$\mathrm{P}$ rimary angioplasty has been shown to improve the outcome of patients with ST segment elevation myocardial infarction (STEMI) as compared with thrombolysis. ${ }^{1-3}$ Despite the clear reduction in restenosis, the benefits of stenting in terms of death or reinfarction remain unclear. The results of our previous study ${ }^{4}$ and all subsequently published trials ${ }^{5-12}$ may have been biased by patient selection, as all of these patients have been randomly allocated to treatment after the initial angiogram. The knowledge of coronary anatomy before the randomisation may have excluded many patients who were subjectively considered unsuitable for stenting, whereas the exclusion of high risk patients and those with unstable haemodynamic conditions may have contributed to reduce benefits of stenting in terms of death and reinfarction. Our previous trial ${ }^{4}$ has also shown that patients excluded from the trial during the study period had a significantly worse outcome. Therefore, we have conducted a prospective randomised trial to investigate the impact of routine stenting, as compared with balloon angioplasty, on combined death or reinfarction in a large cohort of unselected patients with STEMI.

\section{METHODS}

All patients with STEMI who were admitted within the first six hours, or between 6-24 hours if they had persistent symptoms with evidence of ongoing ischaemia, were randomly assigned to stenting or balloon angioplasty. To identify prospectively the actual prevalence of patients suitable or unsuitable for stenting in a large cohort of patients presenting with STEMI, they were randomly allocated to treatment before angiography. Informed consent was obtained from each patient (or from the relatives of patients unable to provide consent) before angiography. Other than refusal to give informed consent or death before randomisation, no exclusion criteria were applied. Our study was approved by the institutional review board. All patients received aspirin (500 $\mathrm{mg}$ ) and heparin (10 $000 \mathrm{IU})$ intravenously before the initial angiography. Coronary intervention was performed according to standard procedure. ${ }^{4}$ The choice of stent and the use of adjunctive IIb/IIIa inhibitors were left to the discretion of the surgeon. After the intervention, all patients received oral aspirin daily, with additional ticlopidine $(250 \mathrm{mg} /$ day) or clopidogrel (after June 1999; $300 \mathrm{mg}$ loading dose followed by $75 \mathrm{mg} /$ day) for four weeks.

\section{Study end points and data collection}

The primary end point was death or recurrent infarction at one year's follow up. Secondary end points were target vessel revascularisation (TVR) and major adverse cardiac events (MACE) at one year's follow up (defined as death, reinfarction, or TVR), as well as angiographic restenosis at six months' follow up. Recurrent infarction was defined as previously described. ${ }^{1}$ The indication for a second intervention had to be substantiated by symptoms or by ECG or scintigraphic evidence of ischaemia at rest or during exercise. Subsequent revascularisation of other coronary arteries did not constitute an end point. All events were reviewed by two cardiologists blinded to treatment assignment.

Quantitative coronary angiograms were analysed by an independent core laboratory (Diagram, Zwolle, the Netherlands) blinded to all clinical data and outcomes.

Abbreviations: CADILLAC, controlled abciximab and device investigation to lower late angioplasty complications; MACE, major adverse cardiac events; PAMI, primary angioplasty in myocardial infarction; STEMI, ST segment elevation myocardial infarction; TIMI, thrombolysis in myocardial infarction; TVR, target vessel revascularisation 
Table 1 Clinical and angiographic characteristics

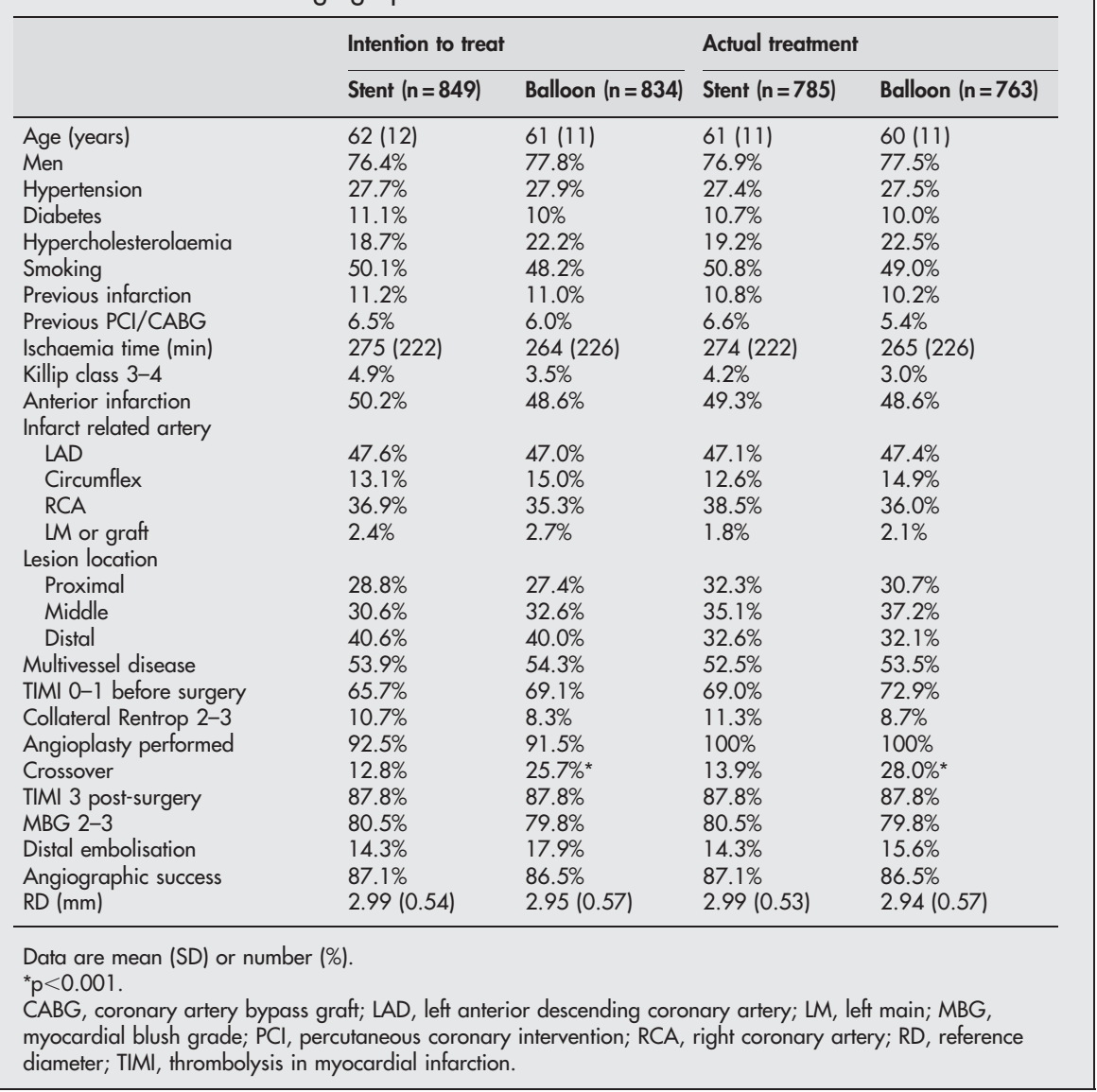

Procedural success was defined as postprocedural TIMI (thrombolysis in myocardial infarction) 3 flow and a residual stenosis $<50 \%$ according to the investigator. Angiographic success was defined as postprocedural TIMI 3 flow and a residual stenosis $<50 \%$ according to the core laboratory. ${ }^{4}$

All patients were reviewed at an outpatient clinic. For patients who died during follow up, hospital records and necropsy data were reviewed. No patient was lost to follow up. Angiographic restenosis was defined as diameter stenosis of $>50 \%$ at quantitative coronary angiography.

\section{Statistical analysis}

Continuous data were expressed as mean (SD) and categorical data as percentages. The analysis of variance was

Table 2 Reasons for exclusion of patients from primary angioplasty or crossover from stent to balloon angioplasty

\begin{tabular}{lcc}
\hline Reason & Balloon group & Stent group \\
\hline Patients who did not undergo primary angioplasty & $(\mathrm{n}=135)^{*}$ \\
Number & 71 & 64 \\
No significant stenosis & $15(21.1 \%)$ & $11(17.2 \%)$ \\
Conservative treatment & $20(28.2 \%)$ & $16(25 \%)$ \\
Early bypass surgery & $25(35.2 \%)$ & $27(42.2 \%)$ \\
Guidewire crossing failure & $11(15.5 \%)$ & $10(15.6 \%)$ \\
Patients in the stent group ( $\mathrm{n}=785)$ who were unsuitable for stenting \\
Number & $109(13.9 \%)$ \\
Complex anatomy & $23.3 \%$ \\
Cardiogenic shock or death in the cath lab & $3.7 \%$ \\
In-stent occlusion & $1.9 \%$ \\
Planned early bypass surgery & $8.3 \%$ \\
Inability to cross lesion with the stent & $7.4 \%$ \\
Diffuse sclerosis or small vessels & $55.3 \%$ \\
\hline \multirow{2}{*}{ *All comparisons (stent versus balloon groups) not significant. }
\end{tabular}

appropriately used for continuous variables. The $\chi^{2}$ test or the Fisher's exact test was used for categorical variables. The difference in event rates between groups during the follow up period was assessed by the Kaplan-Meier method with the $\log$ rank test. A probability value of $p<0.05$ was considered significant.

According to our previous report ${ }^{4}$ and to the inclusion in the current study of all patients with no exclusion criteria, we estimated a combined rate of death or reinfarction at one year of $15 \%$. With an anticipated two sided test for differences in independent binomial proportions at the 5\% significance level with a power of $80 \%, 1450$ patients were required to detect a reduction in a primary end point of 33\% (from 15\% to $10 \%$ ). To overcome any potential conservative treatment and drop out from the study after randomisation, 1683 consecutive patients were finally given random assignment before angiography.

With an anticipated two sided test for differences in independent binomial proportions at the 5\% significance level with a power of $80 \%, 626$ patients were required to undergo angiographic follow up to detect a reduction in angiographic restenosis of 33\% (from 30\% to 20\%).

Data were analysed according to intention to treat and actual treatment analysis.

\section{RESULTS}

\section{Patient population and procedural results}

During the study period, 1702 consecutive patients with STEMI were admitted to our hospital. Nineteen patients were excluded from the study because of death before randomisation or refusal to give informed consent. The remaining 1683 patients were randomly assigned treatment before angiography. Table 1 reports patients' and procedural characteristics 

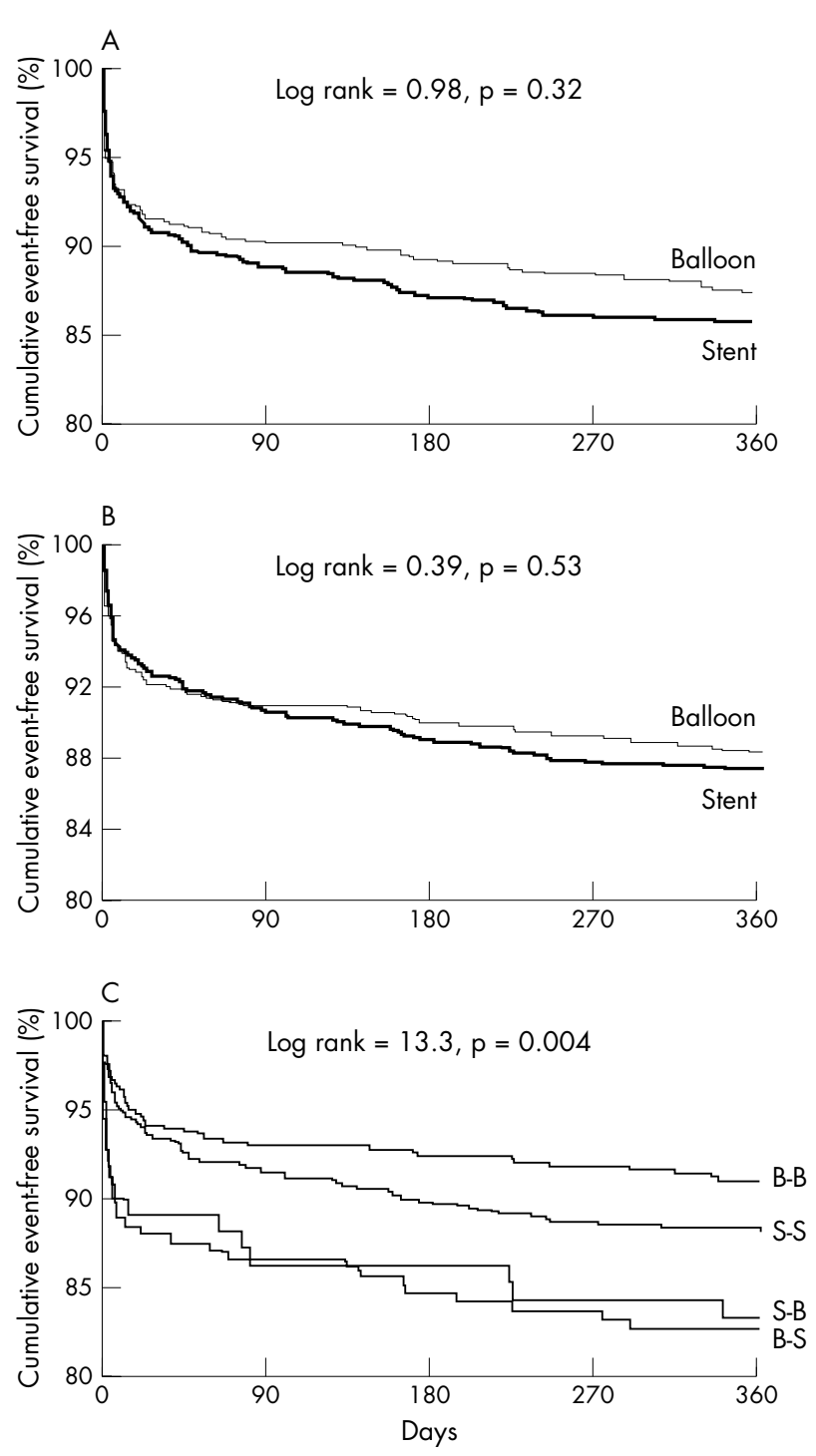

Figure 1 Kaplan-Meier event-free survival curves for combined death or reinfarction according to (A) intention to treat analysis, $(B)$ actual treatment analysis, and (C) analysis of four subgroups according to initial randomisation allocation and final treatment. B-B, randomly allocated to balloon and actually treated with balloon; S-B, randomly allocated to stent but treated with balloon only; B-S, randomly allocated to balloon but treated with stent; S-S, randomly allocated to stent and actually treated with stent.

according to either intention to treat analysis or actual treatment analysis. Except for postprocedural residual stenosis, minimum lumen diameter, and cross over rate, no difference was observed between the groups.

In the stent group $54(6.4 \%)$ patients and in the balloon group $60(7.2 \%)$ patients had no indication for primary angioplasty (table 2 ). The target lesion could not be crossed with a guidewire or balloon in $10(1.2 \%)$ and in 11 patients $(1.3 \%)$ in each group, respectively. Therefore, 1548 patients ( 785 in the stent group and 763 in the balloon group) actually underwent primary angioplasty. Table 1 presents the results according to actual treatment analysis. In 109 patients (13.9\%) randomly assigned to stenting the target lesion was considered unsuitable for stenting and they were treated with balloon angioplasty (table 2). For 214 (28\%) randomly assigned to balloon angioplasty $(\mathrm{p}<0.001)$, bailout stenting was necessary because of dissection or unsatisfactory results after balloon angioplasty. Postprocedural TIMI 3 flow, myocardial blush grade, and distal embolisation did not differ between the groups. Although stenting was associated with a better postprocedural minimum lumen diameter and residual stenosis, no difference in angiographic success was found.

\section{Primary end point}

In intention to treat analysis, combined death or reinfarction did not differ at either the 30 day or the one year follow (fig 1, table 3). Similar data were also observed at actual treatment analysis (fig 1, table 3), even when subsets of patients were analysed (fig 2). Figure 1 shows the one year clinical outcome in cross over patients and in those actually treated according to their random treatment allocation. As expected, cross over was associated with impaired outcome.

\section{Secondary end points}

In intention to treat analysis, TVR and MACE did not differ at either the 30 day or the one year follow (table 3 ).

As table 3 shows, actual treatment analysis data were similar. Table 4 shows the results of quantitative coronary analysis of patients scheduled for routine angiographic follow up at six months $(\mathrm{n}=629 ; 41 \%)$. Stenting was not associated with a significant reduction in TVR despite significant benefits in terms of restenosis.

\section{DISCUSSION}

This randomised trial addressed the actual role of routine stenting in a large cohort of unselected patients undergoing primary angioplasty for STEMI. An early randomisation strategy (before the initial angiography) ensured that all consecutive patients with STEMI were included in this trial, with no exclusion criteria other than failure to obtain informed consent.

The main finding of the current study is that routine coronary stenting for STEMI does not seem to reduce death or reinfarction when compared with balloon angioplasty. Several factors may explain the absence of any impact of stenting on mortality. The survival benefits of primary angioplasty over thrombolysis are related to the higher rate of TIMI 3 flow and lower rate of reinfarction and stroke. ${ }^{1-3}$ In the present study outcomes of stent and balloon were similar in terms of TIMI flow, distal embolisation, and myocardial blush, all major determinants of mortality. ${ }^{13}{ }^{14}$ Therefore, stenting does not seem to improve epicardial or myocardial perfusion. These data have been confirmed by Kastrati et al, ${ }^{15}$ who found no difference between stent and balloon angioplasty for STEMI in terms of myocardial salvage. ${ }^{15}$

Although the restenosis rate in our trial, defined as diameter stenosis $>50 \%$ at follow up, was significantly lower after stenting, the incidence of severe restenosis (diameter stenosis $>70 \%$ or total occlusion) was comparable between the groups (table 4). The absence of clear advantages in terms of repeat revascularisation after stenting, in comparison with previous randomised trials, may also be related to the inclusion in this trial of patients with high risk lesions and to the fact that not all patients underwent routine follow up angiography. ${ }^{16}$ It has previously been shown that routine follow up angiography is associated with an increased rate of TVR. ${ }^{16}$

In the Zwolle trial ${ }^{4}$ and PAMI (primary angioplasty in myocardial infarction) study ${ }^{7}$ of selected patients with strict angiographic inclusion criteria, stenting was associated with an extremely low rate of six month reinfarction (1.6\% and $2.4 \%$ ) and TVR (3.6\% and 7.7\%, respectively). These findings have been confirmed in the CADILLAC (controlled abciximab and device investigation to lower late angioplasty complications) trial, ${ }^{12}$ with rates of reinfarction and TVR at six months in the stent arm (without abciximab) of $1.6 \%$ and $8.3 \%$, respectively. 
Table 3 Clinical outcome at the 30 day and one year follow up according to intention to treat and actual treatment analysis

\begin{tabular}{|c|c|c|c|c|c|c|}
\hline & \multicolumn{2}{|c|}{ Intention to treat* } & \multirow[b]{2}{*}{ RR $(95 \% \mathrm{Cl})$} & \multicolumn{2}{|c|}{ Actual treatment* } & \multirow[b]{2}{*}{$\operatorname{RR}(95 \% \mathrm{Cl})$} \\
\hline & Stent $(n=849)$ & Balloon $(n=834)$ & & Stent $(n=785)$ & Balloon $(n=763$ ) & \\
\hline \multicolumn{7}{|l|}{30 days } \\
\hline Death & $4.2 \%$ & $4.8 \%$ & $0.86(0.54$ to 1.35$)$ & $3.2 \%$ & $4.5 \%$ & 0.71 (0.41 to 1.23$)$ \\
\hline ReMI & $5.9 \%$ & $4.4 \%$ & 1.37 (0.89 to 2.13$)$ & $5.1 \%$ & $3.9 \%$ & $1.6(0.87$ to 2.92$)$ \\
\hline Death/ReMI & $9.2 \%$ & $8.5 \%$ & 1.09 (0.78 to 1.52$)$ & $7.5 \%$ & $7.7 \%$ & 0.99 (0.66 to 1.55$)$ \\
\hline SAT & $3.4 \%$ & $2.2 \%$ & $1.6(0.88$ to 2.91$)$ & $3.7 \%$ & $2.4 \%$ & $1.6(0.88$ to 2.91$)$ \\
\hline TVR & $9.1 \%$ & $8.4 \%$ & $1.09(0.78$ to 1.53$)$ & $6.4 \%$ & $6.0 \%$ & 1.21 (0.73 to 1.94$)$ \\
\hline $\begin{array}{l}\text { MACE } \\
1 \text { year }\end{array}$ & $13 \%$ & $13.4 \%$ & $0.96(0.72$ to 1.27$)$ & $9.2 \%$ & $10.7 \%$ & $0.88(0.61$ to 1.28$)$ \\
\hline Death & $7.1 \%$ & $6.6 \%$ & $1.12(0.76$ to 1.66$)$ & $6.0 \%$ & $5.9 \%$ & $1.03(0.68$ to 1.59$)$ \\
\hline ReMI & $8.4 \%$ & $6.8 \%$ & $1.33(0.9$ to 1.96$)$ & $7.8 \%$ & $6.4 \%$ & $1.32(0.86$ to 2.03$)$ \\
\hline Death/ReMI & $14.0 \%$ & $12.4 \%$ & $1.21(0.91$ to 1.62$)$ & $12.4 \%$ & $11.3 \%$ & $1.16(0.84$ to 1.59$)$ \\
\hline SAT & $4.5 \%$ & $3.0 \%$ & $1.52(0.91$ to 2.53$)$ & $4.8 \%$ & $3.3 \%$ & 1.53 (0.9 to 2.52 ) \\
\hline TVR & $19.6 \%$ & $20.7 \%$ & $0.98(0.78$ to 1.22$)$ & $17.3 \%$ & $19.3 \%$ & $0.89(0.7$ to 1.15$)$ \\
\hline MACE & $26.3 \%$ & $27.6 \%$ & $0.99(0.81$ to 1.21$)$ & $23.1 \%$ & $25.3 \%$ & 0.92 (0.74 to 1.14 ) \\
\hline
\end{tabular}

*All comparisons (stent versus balloon groups) not significant.

$\mathrm{Cl}$, confidence interval; MACE, major adverse cardiac events (death, reinfarction, or target vessel revascularisation (TVR)); ReMl, recurrent myocardial infarction;

$\mathrm{RR}$, relative risk; SAT, subacute thrombosis.

A recent randomised study ${ }^{17}$ conducted in highly experienced centres without strict angiographic exclusion criteria (thus, close to the real world situation) resulted in a "relatively poor" outcome after coronary stenting with rates of reinfarction and TVR at six months of $5.5 \%$ and $17 \%$, respectively. These data are consistent with our findings, suggesting that in all unselected patients presenting with STEMI, stenting does not seem to improve significantly the rates of reinfarction and TVR compared with balloon angioplasty.

In addition, among all patients presenting with STEMI who were randomly allocated before the initial angiography, the actual prevalence of unsuitable lesions for stenting was $13.9 \%$. These patients were actually excluded from all previous randomised trials.

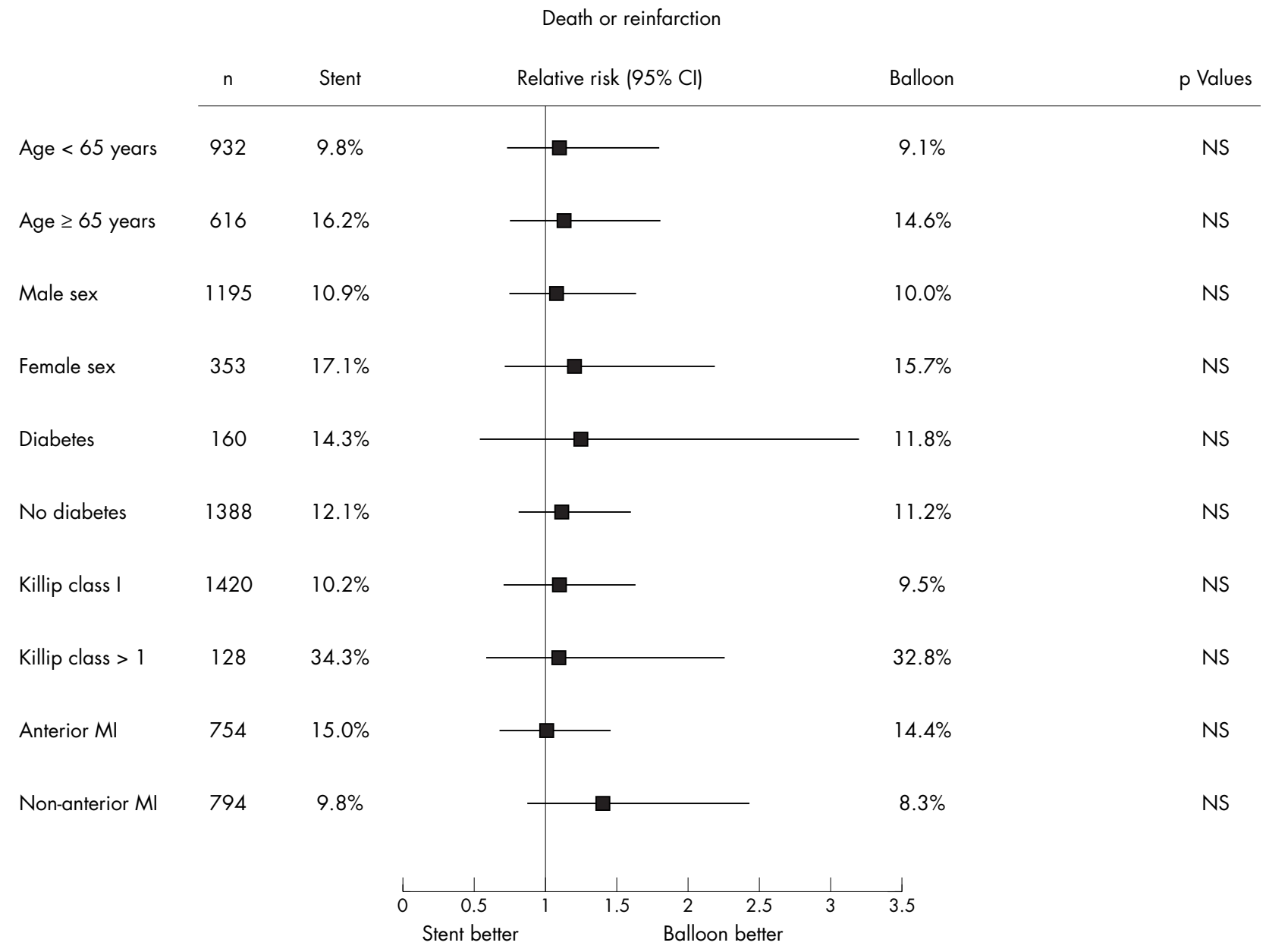

Figure 2 Relative risk and 95\% confidence intervals $(\mathrm{Cl})$ of the primary end point (death or reinfarction) at one year's follow up in subsets of patients assigned to balloon or stenting. 
Table 4 Quantitative coronary angiography in 629 patients undergoing routine angiographic follow up

\begin{tabular}{|c|c|c|c|}
\hline & $\begin{array}{l}\text { Stent } \\
(n=306)\end{array}$ & $\begin{array}{l}\text { Balloon } \\
(n=323)\end{array}$ & $\mathrm{p}$ Value \\
\hline Reference diameter $(\mathrm{mm})$ & $3.05(0.53)$ & $2.99(0.56)$ & NS \\
\hline \multicolumn{4}{|l|}{$M L D(m m)$} \\
\hline Post-PCI & $2.5(0.46)$ & $2.17(0.52)$ & $<0.0001$ \\
\hline Follow up & $1.62(0.82)$ & $1.51(0.78)$ & NS \\
\hline \multicolumn{4}{|l|}{ Stenosis (\%) } \\
\hline Post-PCl & $17.6(10.3)$ & $27.3(10.8)$ & $<0.0001$ \\
\hline Follow up & $44.5(25.1)$ & $48.3(23.3)$ & 0.053 \\
\hline \multicolumn{4}{|l|}{ Restenosis } \\
\hline$>50 \%$ & $34.3 \%$ & $42.4 \%$ & 0.037 \\
\hline$>70 \%$ & $14.1 \%$ & $13.9 \%$ & NS \\
\hline Total occlusion & $11.4 \%$ & $10.8 \%$ & NS \\
\hline $\begin{array}{l}\text { Results are presented as } m \\
\text { MLD, minimum lumen diar } \\
\text { coronary intervention. }\end{array}$ & $\begin{array}{l}\text { an (SD). } \\
\text { eter; NS, n }\end{array}$ & nificant; $P$ & ercutaneous \\
\hline
\end{tabular}

Although the beneficial effect of drug eluting stents on TVR have been shown in elective cases, ${ }^{18-19}$ and the initial results showed the feasibility of drug eluting stents for STEMI, ${ }^{20}$ the issue of their safety for STEMI has not been established. Future randomised studies, without strict inclusion criteria, should be conducted to provide a cost-benefit analysis of an unrestricted use of drug eluting stents in this high risk subset of patients.

\section{Limitations}

Even though randomisation before angiography was considered a more objective method to avoid patient selection bias, it may have resulted in overuse of stenting, even in unfavourable lesions. Since the benefits of adjunctive glycoprotein IIb/IIIa inhibitors have been shown only recently ${ }^{12}{ }^{17}$ and their beneficial effect on mortality in the setting of STEMI has yet to be clarified, ${ }^{21}$ only $5 \%$ of our patients received this additional drug and no distal protection devices were used in this series.

We modified our post-stenting antiplatelet regimens during the study period when it became clear that clopidogrel has a similar effect to ticlopidine..$^{22-24}$

\section{Conclusion}

Compared with balloon angioplasty, routine coronary stenting does not seem to reduce death and reinfarction in a large cohort of unselected patients with STEMI.

\section{ACKNOWLEDGEMENTS}

We are indebted to Vera Derks for editorial assistance and to the staff of DIAGRAM, BV, Zwolle, the Netherlands, for their core laboratory and statistical expertise.

\section{Authors' affiliations}

H Suryapranata, G De Luca, A W J van 't Hof, J P Ottervanger, J C A Hoorntje, J-H E Dambrink, A T M Gosselink, F Zijlstra, M-J de Boer, Department of Cardiology, ISALA Klinieken, Hospital De Weezenlanden, Zwolle, the Netherlands

\section{REFERENCES}

1 Zijlstra F, de Boer MJ, Hoorntje JC, et al. A comparison of immediate coronary angioplasty with intravenous streptokinase in acute myocardial infarction. N Engl J Med 1993;328:680-4.
2 Grines $\mathrm{CL}$, Browne KF, Marco J, et al. A comparison of immediate angioplasty with thrombolytic therapy for acute myocardial infarction. The Primary Angioplasty in Myocardial Infarction Study Group. N Engl J Med 1993:328:673-9.

3 Zijlstra F, Hoorntje JCA, de Boer MJ, et al. Long-term benefit of primary angioplasty as compared with thrombolytic therapy for acute myocardial infarction. N Engl J Med 1999;341:1413-9.

4 Suryapranata H, van ' $t$ Hof A, Hoorntje JCA, et al. Randomised comparison of coronary stenting with balloon angioplasty in selected patients with acute myocardial infarction. Circulation 1998;97:2502-5.

5 Antoniucci D, Santoro GM, Bolognese L, et al. A clinical trial comparing primary stenting of the infarct-related artery with optimal primary angioplasty for acute myocardial infarction: results from the Florence randomised elective stenting in acute coronary occlusion (FRESCO) trial. J Am Coll Cardiol 1998;31:1234-9.

6 Rodriguez A, Bernardi V, Fernández $M$, et al. In-hospital and late results of coronary stents versus conventional balloon angioplasty in acute myocardial infarction (GRAMI trial). Am J Cardiol 1998;81:1286-91.

7 Grines CL, Cox DA, Stone GW, et al. Coronary angioplasty with or without stent implantation for acute myocardial infarction. Stent Primary Angioplasty in Myocardial Infarction Study Group. N Engl J Med 1999:341:1949-56.

8 Saito S, Hosokawa G, Tanaka S, et al. Primary stent implantation is superior to balloon angioplasty in acute myocardial infarction: final results of the primary angioplasty versus stent implantation in acute myocardial infarction (PASTA) trial. PASTA Trial Investigators. Catheter Cardiovasc Interv 1999;48:262-8.

9 Millard L, Hamon M, Khalife K, et al. A comparison of systematic stenting and conventional balloon angioplasty during primary percutaneous transluminal coronary angioplasty for acute myocardial infarction. STENTIM-2 Investigators. J Am Coll Cardiol 2000;35:1729-36.

10 Suryapranata $H$, Ottervanger JP, Nibbering E, et al. Long term outcome and cost-effectiveness of stenting versus balloon angioplasty for acute myocardial infarction. Heart 2001:85:667-71.

11 Zhu MM, Feit A, Chadow H, et al. Primary stent implantation compared with primary balloon angioplasty for acute myocardial infarction: a meta-analysis of randomised clinical trials. Am J Cardiol 2001;88:297-301.

12 Stone G, Grines CL, Cox AD, et al. Comparison of angioplasty with stenting with or without abciximab, in acute myocardial infarction. N Engl J Med 2002;346:957-66

13 van 't Hof AW, Liem A, Suryapranata H, et al. Angiographic assessment of myocardial reperfusion in patients treated with primary angioplasty for acute myocardial infarction: myocardial blush grade. Circulation 1998;97:2302-6.

14 Henriques JP, Ziilstra F, Ottervanger JP, et al. Incidence and clinical significance of distal embolisation during primary angioplasty for acute myocardial infarction. Eur Heart J 2002;23:1112-7.

15 Kastrati A, Mehilli J, Nekolla S, et al. STOPAMI-3 Study Investigators. A randomised trial comparing myocardial salvage achieved by coronary stenting versus balloon angioplasty in patients with acute myocardial infarction considered ineligible for reperfusion therapy. J Am Coll Cardiol 2004:43:734-41.

16 Ruygrok PN, Melkert R, Morel MA, et al. Does angiography six months after coronary intervention influence management and outcome? Benestent II Investigators. J Am Coll Cardiol 1999;34:1507-11.

17 Antoniucci D, Migliorini A, Parodi G, et al. Abciximab-supported infarct artery stent implantation for acute myocardial infarction and long-term survival: a prospective, multicenter, randomised trial comparing infarct artery stenting plus abciximab with stenting alone. Circulation 2004; 109:1704-6.

18 Moses JW, Leon MB, Popma JJ, et al. SIRIUS Investigators. Sirolimus-eluting stents versus standard stents in patients with stenosis in a native coronary artery. N Engl J Med 2003;349:1315-23.

19 Stone GW, Ellis SG, Cox DA, et al. A polymer-based, paclitaxel-eluting stent in patients with coronary artery disease. N Engl J Med 2004;350:221-31.

20 Lemos PA, Saia F, Hofma SH, et al. Short- and long-term clinical benefit of sirolimus-eluting stents compared to conventional bare stents for patients with acute myocardial infarction. J Am Coll Cardiol 2004;43:704-8.

21 Eisenberg MJ, Jamal S. Glycoprotein Ilb/llla inhibition in the setting of acute ST-segment elevation myocardial infarction. J Am Coll Cardiol 2003;42:1-6.

22 Moussa I, Oetgen M, Roubin G, et al. Effectiveness of clopidogrel and aspirin versus ticlopidine and aspirin in preventing stent thrombosis after coronary stent implantation. Circulation 1999:99:2364-6.

23 Bertrand ME, Rupprecht HJ, Urban P, et al. Investigators FT. Double-blind study of the safety of clopidogrel with and without a loading dose in combination with aspirin compared with ticlopidine in combination with aspirin after coronary stenting: the clopidogrel aspirin stent international cooperative study (CLASSICS), Circulation 2000; 102:624-9.

24 Bhatt DL, Bertrand ME, Berger PB, et al. Meta-analysis of randomised and registry comparisons of ticlopidine with clopidogrel after stenting. J Am Coll Cardiol 2002;39:9-14. 